\title{
LITERATURE
}

$\infty$

Ewa Ziomek

The John Paul II Catholic University of Lublin

ewaziomek92@gmail.com

\section{Aestheticization of Serial Killers in Contemporary Crime Literature and Film}

\begin{abstract}
Fictional serial killers often appear attractive, since the authors and film directors deliberately employ certain techniques to depict the villains as seductive and manipulate readers/spectators into forming a bond with devious protagonists. This article argues that by virtue of different stylistic and literary devices, the villains presented in contemporary texts are aestheticized. Moreover, it also explains why the reader/audience often sympathizes with the murderer rather than the victim.
\end{abstract}

Key words: serial killers, aestheticization, murder, violence, crime, literature, film.

\section{Introduction}

Fictional villains, antiheros and serial killers have always been mysterious and thus intriguing. Discovering their motives, reading their minds, and searching for clues have excited a great deal of murder fiction readers as well as thriller viewers. The satisfaction derived from this kind of literature and film is multidimensional, including "the control over disorder, the pleasure of pattern-discovering, the identification with a strong representative of the law, and of course the enjoyment, from the reader's secure position, of the murder as art or simply an intellectual game" (Allue 2002, 7). While reading a detective story, one can, without any consequences, disregard ethics and instead focus on aesthetics. This article argues that watching a crime film is an aesthetic game that does not observe the laws of moral judgment. It is the viewer's choice whether to identify with a heroic detective or an intriguing murderer. 
One could say that the literary masterpieces of Agatha Christie, Arthur Conan Doyle, or Thomas Harris introduce the readers into the world of mystery and puzzle. No wonder this branch of literature has been so popular among different generations. Not only does contemporary culture offer a wide range of novels about murder, but it also produces films and TV series about crimes which attract a vast audience. This article, thus, supports the thesis that the figure of serial killer is aestheticized on many levels in order to attract the readers and viewers and make them engage with the villain.

Accordingly, this paper refers to Thomas De Quincey's theory of murder with a view to proving that murder may be considered not only an atrocious crime, but also art. Additionally, the article analyzes Joel Black's work The Aesthetics of Murder and examines the aestheticization of violence, the process which is becoming ubiquitous in American culture. The consecutive subsections are dedicated to the role of the reader/ viewer as the witness of murder as well as the murderer-reader/viewer relationship. Furthermore, the paper provides the reasons for popularization of sensationalistic murder literature after the humanitarian revolution and explores the significance of pain as a source of the sublime, discussing such notions as body-horror and carnography. Finally, the article investigates the cathartic role of murder in contemporary crime literature and film.

\section{On Murder Considered as One of the Fine Arts}

The idea of considering murder in terms of art was first introduced by Thomas De Quincey, a prominent English essayist and a literary critic. Robert Morrison (2009) in The English Opium-Eater: A Biography of Thomas De Quincey claims that De Quincey "wrote some of the most eloquent and searching prose of the nineteenth century." As a writer of the Romantic era, he had a close relationship with such notable literary figures as William Wordsworth and Samuel Taylor Coleridge. Even though he is mostly known for his Confessions of an English Opium-Eater (1821), it is his three essays on murder ${ }^{1}$ that "range from brilliantly funny satiric high jinks to penetrating cultural criticism, and had a remarkable influence on crime, terror and detective fiction, as well as on the rise of nineteenth-century decadence" (Morrison 2009). De Quincey's criticism on murder scandalizes and evokes ambiguous reactions, yet it is still applicable to contemporary trends in crime fiction.

"On Murder Considered as One of the Fine Arts" (1827), the first essay in the collection, consists of De Quincey's thoughts on two different approaches towards murder. He perceives murder as an act that can be treated morally, but also aesthetically.

Thomas De Quincey wrote three essays on murder: "On Murder Considered as One of the Fine Arts" (1827), "A Second Paper on Murder Considered as One of the Fine Arts" (1839) and "Postscript" (1854), which were published as a collection of essays entitled Murder Considered as One of the Fine Arts (1854). 
He writes: "everything in this world has two handles. Murder, for instance, may be laid hold of by its moral handle (...); or it may also be treated aesthetically, as the Germans call it - that is, in relation to good taste" ([1827] 2015). De Quincey distinguishes two stages of murder, which determine how it may be treated. First, if a murder has not been committed or is not being committed, it should, by all means, be treated morally, since there is still a chance of preventing it from happening. However, when a murder has already been committed, there is nothing else that can be done about it but to appreciate it from an aesthetic perspective: "enough has been given to morality; now comes the turn of Taste and the Fine Arts" ([1827] 2015). De Quincey claims that a tragedy of murder, which appears to be ghastly from the moral point of view, may be a "meritorious performance" ([1827] 2015) when approached from an aesthetic perspective. Referring to De Quincey's approach towards murder, Joel Black states:

De Quincey's outrageous idea that, under the appropriate conditions, cold-blooded murder can achieve artistic legitimacy has been viewed by most readers as a curious, but minor, example of rhetorical and artistic virtuosity (...). By treating murder as an art form, De Quincey demonstrated the aesthetic subversion of the beautiful by the sublime, and more generally, the philosophical subversion of ethics by aesthetics. (Black 1991, 15)

\section{The Aesthetics of Murder and Aestheticization of Violence}

Referring to Thomas de Quincey, Joel Black analyzes murder from an aesthetic perspective and, consequently, poses a question of whether a murderer may be called an artist. He claims that murder can be experienced aesthetically; therefore, the murderer can be regarded as an artist who specializes in destruction rather than creation:

If any human act evokes the aesthetic experience of the sublime, certainly it is the act of murder. And if murder can be experienced aesthetically, the murderer can in turn be regarded as a kind of artist - a performance artist or anti-artist whose specialty is not creation but destruction. (Black 1991, 14)

The beholder is compelled by violent acts, sometimes even admiring the "creator-destructor" who, in that regard, becomes an artist. Irrespective of the fact it is murder that is considered an artefact, the murderer has to be called an artist if his performance evokes an aesthetic response in the spectator (Black 1991, 39).

Violence, and murder in particular, described in crime fiction and presented in films is aestheticized in many ways. Compelling depictions of violence beautify the horrific aspect of murder and encourage readers/spectators to search for the suppressed, primal feeling of curiosity about the death. Since "our popular/public understanding of 'art' has culturally mutated" (Schneider 2001, 67), even a petrifying murder is frequently (re)presented as an artistic product and/or an artistic performance. Showing an artistic 
aspect of violence results mainly from the attempt to humanize the murderer and make beholders acknowledge their "dark side," which relishes the sophisticated game of killing:

And when the human-like monsters populating recent films (...) turn murder into an artistic product, an artistic performance or some bizarre combination of the two, consumers of these fictions are once again encouraged, occasionally forced, to acknowledge a side of themselves they normally keep hidden, even from themselves - a side that enjoys, appreciates and admires the display of creative killings. (Schneider 2001, 75)

Encouraged to "become killers," spectators of crime films or series can vicariously experience the forbidden and remain guiltless.

Apart from the fact that in contemporary crime film violence is made more aesthetically admirable, meaning it is presented as art rather than a repelling act, the very concept of art has changed its meaning: “(...) 'art' itself became more open to and associated with notions of 'shock,' transgression and offensiveness, with the violation of standing cultural and conceptual categories" (Schneider 2001, 76). An aesthetic experience derived from art is nowadays more difficult to define as pleasurable. Schneider (2001) tells us that occasionally it is even the opposite of pleasure: "aesthetic experience comes in a wide variety of forms, after all, and some are a great deal less pleasurable than others" (76). Art is no longer associated only with good taste, but also with shock and scandal. It evokes an aesthetic experience, which elicits deeply hidden, forbidden desires from the beholders of an artistic product or artistic performance. By means of aestheticization, even murder may be considered art.

The aestheticization of violence in films is mostly focused on making it more appealing and attractive in order to encourage the viewers to root for the killer instead of the victim. Some spectators tend to succumb to a murderer's tempting or even seductive character in the performance, and, enchanted by the killer, do not consider violent scenes repulsive. On the contrary, by virtue of the way in which a film has been shot and the devices used to aestheticize the violence, the drastic scenes are beautified:

As a result of specific stylistic machinations, the segments that contain the violence have become more visually and viscerally attractive than all the segments that do not contain any violence. In this usage, the concept of aestheticization is isomorphous with the concept of beauty. (Gronstad 2008, 40-41)

However, the notion that violence may be beautified is often questioned. Gronstad (2008) explains that "while some endorse the violence because it is presented in a beautifying manner, others condemn it for that very reason" (41). The proponents of the aestheticization of violence argue that aesthetics redeem ethics; ergo, it is allowed to ignore ethics, provided that it leads to the aesthetic experience. However, the opponents claim that cruelty is obscured by beauty and therefore, the spectator is allured to 
enjoy violence, which is, by all means, unethical (41). Accordingly, there are different ways of embellishing screen violence. Not always is the effect of beautified violence achieved by the usage of visual devices. Sometimes, murder is justified by an appropriate scenario, as we read in Prince (2000): "screen violence is made attractive, whether by dressing it up in special effects or by embedding it in scenarios of righteous (i.e., morally justified) aggression" (32). For instance, a reader/spectator may be encouraged to diminish the seriousness of the committed murder, when the killer is presented as an avenger killing only those who deserve it.

Aestheticizing screen violence is also planned to alienate the audience from the real world, where brutality is anything but beautiful. First, violence is made appealing in order to attract the viewers and uncover their hidden feelings, but secondly, it is aestheticized so that it does not look real and dangerous like the violence presented in documentaries: "no matter how graphic the violence, the aestheticizing of it enables the viewer to enjoy it, because it reminds them that it is not real, compared to gory scenes from documentary films which in contrast are harder to watch" (Rodbjerg 2015). In order to make screen violence a pleasurable aesthetic experience for the viewer, a lot of effort has to be put into the process of shooting the film. At the same time, the viewers have to feel distant from screen violence so as not to be overwhelmed by the guilt associated with their enjoyment of the presented violence. Prince (2000) argues:

Changing camera positions, controlled lighting, montage editing, music, and special effects create significant aesthetic pleasure and emotional distance for viewers, who can use these cues as a means of insulating themselves from the depicted violence. The episodes can be enjoyed because they are perceived as being 'not real' by virtue of their elaborate design and special effects. (28)

The aestheticization of screen violence is, therefore, employed to picture murder as an artistic product or artistic performance, to beautify the violence to expose beholders' hidden feelings, and, finally, to let viewers feel distant from screen violence so that they will not consider it real. By making violence aestheticized the recipient suspends morality and instead focuses on the aesthetic sensations: "our reactions to these fictional representations of murder may range from horror to admiration, but whatever shock we experience will consist of aesthetic astonishment rather than of moral outrage" (Black 1991, 9).

\section{Mapping the Aesthetics}

Regarding the aesthetics of murder, there are various angles from which a piece of literature and, analogically, film may be approached. Joel Black distinguishes four types of literary subgenres describing murder and comments on their artistic status (see Figure 1). 


\section{MURDERER}

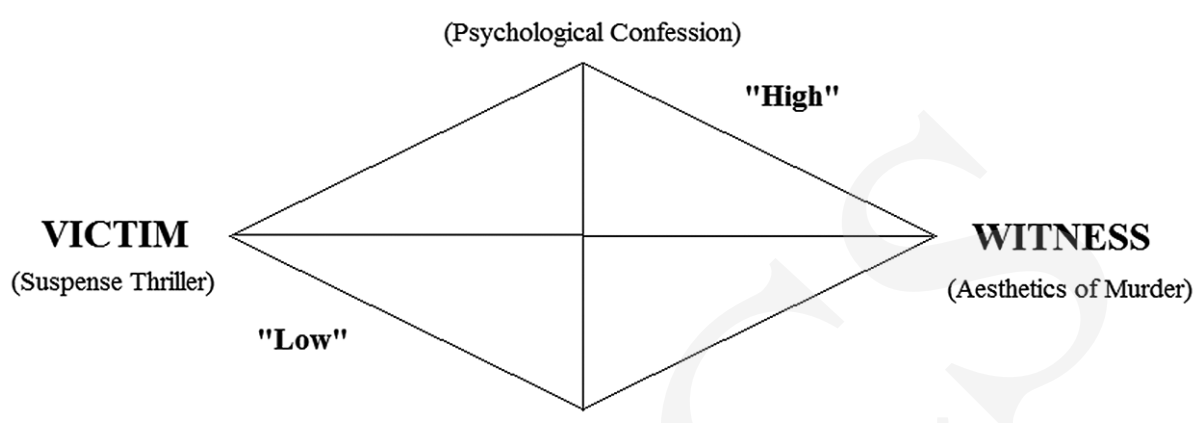

DETECTIVE

(Detective Story / Murder Mystery)

Figure 1. The diagram shows a general typology of the aesthetics of murder (Black 1991, 66).

Accordingly, murder may be presented from four different perspectives: the perspective of the murderer, the witness, the detective, and the victim. Analogically, Black enumerates four types of literary narratives: psychological confession, aesthetics of murder, detective story/murder mystery, and suspense thriller. At the same time, he claims that not all the murder narratives may be granted the same artistic status. There are "high artistic literary forms" (66), such as Shakespeare's psychological dramas or Dostoyevsky's psychological novels, which focus on the murderer and his/her perception of the story, shifting the reader's attention from the victim's point of view. On the other hand, there are "popular subliterary genres of questionable artistic status" (66), like detective story/murder mystery and suspense thriller, which depict the detective's cleverness while helping a powerless murder victim. Additionally, Black differentiates "the quasi-artistic form," employed for instance by De Quincey in literature and by De Palma in films, which presents the aesthetics of murder by focusing not on the killer's, detective's, or victim's perspective but on the point of view of the witness, who vicariously experiences murder (66). By virtue of the fact that the process of aestheticization is mainly observed in the artistic or quasi-artistic literary and cinematic forms, this article focuses on the perspectives of two parties: the murder witnesses and the murderers themselves.

\subsection{Identification with the Witness}

While reading a murder story or watching a horror film one is encouraged or, to be precise, persuaded, to choose different standpoints - not necessarily the victim's perspective. Black (1991) writes that the identification with the murder witness, instead of the murder victim, creates a multifaceted aesthetic which connects the elements of the high artistic literary form (psychological confession) with the allegedly inferior subliter- 
ary genres like thrillers or detective stories. Choosing the witness's viewpoint results in joining the perspective of the helpless murder victim and the murderers themselves (67).

In contradistinction to the victim's perspective, both the murder witness and reader/viewer do not have to bear the suspense, since they observe the crime vicariously: "identification with the murder witness rather than exclusively with the murder victim allows the reader or spectator to experience terror-at-a-distance, so to speak, terror without the lurid terror of suspense" (Black 1991, 67). The witness is not subjected to the killer's fury; therefore, his/her position is safe as s/he is not exposed to any attack. Such a feeling of safety enables both the murder witness and the reader/viewer to forget about the victim's terror and lean towards the mysterious murderer (67).

The fact that the murder witness sees a crime and does not intervene or, as in the reader's/viewer's case, is not able to intervene, shows them in a bad light. After all, the witness may become an accomplice to the murder: "the witness's voyeuristic fascination with the murderer and his victim implicates him in the murderer's guilt" (Black 1991, 106). Being the beholder of murder, just like being the beholder of a piece of art, the witness is prejudiced by what s/he sees and the way s/he sees it, and thus cannot be innocent (106). However, the witness remains "innocent" by being excused, since, all in all, $\mathrm{s} /$ he is just a witness, not the murderer, even though a clear relationship between both of them is evident:

'Guilty' murderer and 'innocent' witness are united, not only by the aesthetic bond between artist and beholder, actor and voyeur, but by an epistemological bond of shared knowledge mediated through their secret relation to a dead body. (106)

Black dares to say that the relationship between the killer and the observer "has a distinctly erotic character" (106). There is a mysterious intimacy between them as they share the moment of standing, close or far, over the victim's dead body.

\subsection{Sympathizing with the Murderer}

In Thomas Harris' Hannibal Lecter series it is the killer that is presented as a sophisticated aesthete who eats the rude. Dexter Morgan, the forensic scientist who in his free time kills other killers, is just another example of the fictional murderer, who is depicted in such a way so as to encourage the viewers to sympathize with him. In contemporary literature and media, the reader/viewer is, more often than not, lured to sympathize with the murderer, and, thus, takes the perspective of the perpetrator instead of that of the murder witness. In what follows, in order to appreciate the aesthetic value of fiction, we have to put our conscience aside and "forget or at least diminish the role of the victims" (Allue 2002, 10). When our "focus is shifted from the point of view of the victim to that of the murderer" (Black 1991, 60), we appreciate the aesthetics of murder more. It is undeniable that certain types of anti-heroes arouse our interest and sympathy: "the thrill and horror evoked by murder narratives bring us close to these 
'others,' who hold us in their thrall because, on the one hand, they are so like us, and on the other, so different," says David F. Schmid, a cultural analyst, in the interview with Patricia Donovan (Donovan 2016). Sarah L. Knox (1998) asserts that sometimes the reader even "identifies with the figure of murderer, remaining always in the sufficient remove (theoretically) to maintain ethical position on the crime while aesthetically appreciating it" (204).

Murray Smith elaborately describes such relations between the anti-hero and the reader/viewer. In his book Engaging Characters: Fiction, Emotion and the Cine$m a$ (1995), Smith delineates a "structure of sympathy," which consists of particular "levels of engagement" (2). The readers or the spectators create a relationship with a villain, and, depending on the type of narrative, they can engage with an anti-hero to a certain extent (74). Smith distinguishes three levels of engagement: recognition, alignment and allegiance. ${ }^{2}$ The first level, recognition, is related to simply recognizing the character by the reader/viewer (82). The second level, alignment, establishes how "spectators are placed in relation to characters in terms of access to their actions, and to what they know and feel" (83). When the spectator reaches the third level of engagement, allegiance, $\mathrm{s} / \mathrm{he}$ is able to evaluate their acts and construct "moral structures, in which characters are organized and ranked in a system of preference" (84).

Smith also addresses the fact that in order to align with anti-heroes, the viewer has to find in them "a morally desirable (or at least preferable) set of traits, in relation to other characters within the fiction" (188). Searching for merits in a villain's character may be difficult without a "suspension of values" and creating an internal "system of values," in other words, the moral structure (189). Smith divides moral structures into the Manichean structure and the graduated moral structure. The Manichean structure casts characters as good or evil, without any hesitation in relation to their character in the story (203), whereas the graduated moral structure depicts characters as not entirely good or bad, but rather as hybrids possessing positive and negative traits (209). A suspension of values and creating an internal system of values make it possible to "sympathize with characters which outside their particular moral structure would appear repugnant and undesirable" (Rodbjerg 2015).

Having created an internal system of values, the reader/viewer may now reach the third level of engagement, in other words, align with the murderer. Smith (2011) distinguishes two kinds of allegiance that one may form with a villain: partial and perverse. In his essay, Smith elaborates on a partial allegiance which concerns villains who, in spite of committing crimes, are presented as human beings. They take care of their families, have their own moral codes and act according to the values they hold. They are often portrayed as vulnerable, sensitive, anxious and frustrated (84), hence the spectators choose to perceive them as human beings rather than monsters. They

2 He also mentions empathy, yet it is placed outside the structure of sympathy, since it is evoked involuntarily by "affective mimicry," for instance, when an anti-hero is suffering or showing fear (Smith 1995, 104). 
frequently turn a blind eye to the fact that the villains are able to "flout moral and other constraints with impunity" (80).

Regarding perverse allegiance, Smith (1999) focuses on protagonists that possess perverse traits; however, they are usually also depicted as charming and attractive. Smith calls them "attractive-bad" characters (225-227). The main difference between partial and perverse allegiances is that in the case of partial allegiance, the characters are sympathetic in spite of their perverse nature, whereas in the case of perverse allegiance they are sympathetic because of their perverse nature (Rodbjerg 2015). Scarcely can we encounter a villain with whom we may create a truly perverse allegiance; usually their depictions are aestheticized and they possess some positive values, thus we sympathize with them in spite of their nature forming a partial allegiance. What is more, "no matter how unsympathetic the protagonists appear, there is always one or more characters in the film that make the protagonists look good by comparison" (Rodbjerg 2015).

\section{Relationship between Observing and Participating}

Even though the aestheticization of serial killing is a relatively new phenomenon which has not been thoroughly studied yet, one could pose the question of when the public interest in murder fiction actually started. Sensationalistic murder literature has its roots in the beginnings of nineteenth-century humanitarianism. Karen Halttunen (2001) claims that the "nineteenth-century murder literature offered readers a new kind of excitement and pleasure in the imaginatively voyeuristic entertainment of impulses newly forbidden by humanitarianism" (89). In times when the topics of violence became taboo, it was murder literature that started to describe violent assaults in detail. Halttunen (2001) writes:

In a period when pain was being redefined as an intolerable aspect of human condition, popular murder narratives came to pay close attention to the agonies of murder victims. At a time when the sight and smell of human corpses were becoming repugnant to the living, popular murder literature lingered on their putrefaction. (78-79)

Murder fiction as well as horror literature depicted images of the forbidden and encouraged readers to engage in the imaginative play with the illicit desires (Halttunen 2001, 82). This kind of literary trend was becoming more popular according to the principle that forbidden fruit tastes the sweetest. At the outset of the nineteenth century, murder literature employed new techniques in order to evoke readers' repugnance and fascination. The stories went into detail describing murder weapons and victims' injuries (73). Developments in forensic science made the depictions of dissections even more meticulous (75).

People's interest in violence resulted in creating a "wound culture," which is "the public fascination with torn and open bodies and torn and opened persons, a collective 
gathering around shock, trauma, and the wound" (Seltzer 1998, 1). The nineteenth-century murder literature presented murder as a spectacle. The "shocking scenes," which were supposed to scandalize and horrify the reader, provided accurate testimonies of murder, which Karen Halttunen (2001) calls a "choreography of crime:"

Murder literature (...) focused on the spectacle of murder, treating violence as something that must be imaginatively seen by readers. Murder was a "bloody spectacle," a "shocking scene," a "horrid drama" to be watched in the private theatre created by interiorization. Nineteenth-century accounts offered detailed visual descriptions of murder, carefully sketching what might be called choreography of the crime. (83)

Halttunen writes about murder narratives as the ones that encourage an "aggressive and voyeuristic spectatorship" (86), changing the role of a detached reader to an engaged voyeur. Aggressive spectatorship developed especially after the popularization of the first-person narratives, when the crime was narrated by the murderer himself. Such a stylistic device was employed by the prominent twentieth-century writer, Agatha Christie, who shocked the literary world with her The Murder of Roger Ackroyd (1926) and established new standards of crime fiction.

Taking the consideration of the reader's engagement a step further, the question should be posed whether the readers/viewers not only observe the violence, but also participate in it. Obviously, they cannot stop the fictional murderer, yet they become emotionally engaged in the murder. Karen Halttunen (2001) argues that:

In crafting the role of the reader as onlooker to the violence, nineteenth-century murder literature explored the problematic relationship between watching and participating in such violence, thus suggesting the reader's moral complicity in the murderer's terrible crime. (89-90)

She also addresses the fact that the nineteenth-century murder literature established a very problematic relationship between violence and the "imaginative spectator" who is exposed to this violence. Ultimately, by reading murder literature or watching a crime TV series the beholder is implicated "in the murderer's terrible guilt" (62).

\section{Pain, Body-Horror and Carnography}

The phenomenon which Halttunen and Seltzer call "a spectacle of murder," was already discussed by the eighteenth-century philosopher, Edmund Burke, who, in his consideration, focuses on pain and its impact on the audience. This British-Irish theorist as well as the author of the treatise A Philosophical Enquiry into the Origin of Our Ideas of the Sublime and Beautiful, writes that "it is a common observation that objects which in the reality would shock are (...) the source of a very high species of pleasure" 
([1757] 1990, 41). Therefore, one could say that one can derive pleasure from crime fiction and film, precisely because they expose the readers/viewers to shock.

At the beginning of the nineteenth century, murder literature took an interest in death and the body in pain. Out of many various techniques of sensationalism, the most frequently employed one was body-horror focused on the violent death (Halttunen 2001, 73). Often body-horror manifested itself in the detailed descriptions of the victim's corpse (74). Halttunen states:

The most horrifying cases of corpse disposal involved corpse dismemberment, which had the effect of graphically prolonging the violence of the murder beyond death. Indeed, these accounts tended to relate the murder quickly, then take their time in tracing the dismemberment and, typically, burning of the corpse. (75)

The relationship between revulsion and desire or excitement reshaped the cultural meaning of pain and death: "the same generation that discovered pain to be intolerable and death repulsive, discovered their pornographic possibilities as a source of dreadful pleasure, precisely because their unacceptability made them obscene" (66).

Sexual pornography and murder literature were closely related by virtue of their tendency towards fusing violence with sex as well as by their mutual obscenity and interest in rape-murders, crimes of passions, prostitute-killings and so forth. In such depictions of body-horror, murder literature honored an obligation of enabling its readers to voyeuristically watch others suffer (Halttunen 2001, 83). Burke ([1757] 1990) argues that it is not uncommon to derive pleasure from watching someone's pain: "I am convinced we have a degree of delight, and that no small one, in the real misfortunes and pains of others" (42).

The connection between hard-core horror and hard-core pornography is aptly captured in the word "carnography," the term which bridges the carnality of the two genres (Pinedo 1997, 61). Not only does the horror film violate taboos, just as pornography does, but the genre also exposes "the secrets of the flesh, to spill the contents of the body" (61). Pinedo quotes Richard Dyer who says that "both [porn and horror] are disreputable genres because they engage the viewer's body, elicit physical responses such as fear, disgust, and arousal in indeterminate combinations, and thereby privilege the degraded half of the mind-body split (61). Both horror and porn are interested in crossing the bodily boundaries by exposing what is concealed and by revealing recess of the body, "porn through carnal knowledge and horror through carnage" (61).

\section{Cathartic Role of Murder}

While discussing the aestheticization of murder and the murderer, it is vital to mention the cathartic role of the spectacle of murder. According to Aristotle, every tragedy should arouse "pity and fear in such a way as to accomplish a catharsis of such emo- 
tions" (Baldick 2001, 35). One may think that the philosopher referred only to the theatre and emotions involved in experiencing a play. The Concise Oxford Dictionary of Literary Terms defines "catharsis" as "the effect of 'purgation' or 'purification' achieved by tragic drama" (Baldick 2001, 35). It is not an exaggeration to say that "tragedy" or "tragic drama" do not relate only to theatre, but also to fiction.

In The Aesthetics of Murder (1991), Joel Black asserts that "most murders involve some kind of cathartic mechanism" (189). By reading sensationalistic fiction or watching a crime TV series we expose ourselves to murders and therefore, experience pity and fear, which accompany our purification of negative emotions and inner cruelty:

the experience of watching fictional violence can be emotionally and morally beneficial, since it contributes to a purging of destructive impulses in the viewer (...). Fictional violence acts as a safety valve which mollifies whatever violent impulses the viewer may possess. (Gronstad 2008, 32)

Through fiction or visual media readers/viewers may re-experience certain emotions without the need of experiencing them in reality: "the spectators in turn re-experience their own latent feelings of pity and fear, but in a simulated rather than actual fashion, and the text represents the means by which they can undertake this vicarious process" (Gronstad 2008, 36).

Murder presented in fiction, whether in literature or visual media, has its cathartic value. Engaged in a fictional crime, one is allowed to discover feelings that otherwise would be inappropriate. Acting as a voyeur who observes the murderer from a sufficient distance, one may vicariously experience feelings which he/she would normally have to suppress.

\section{Conclusions}

Analyzing the process of aestheticization of murder, one encounters various theories concerning murder literature and film. One of the most fundamental examples of criticism with regard to murder as art is the theory presented by Thomas De Quincey in "On Murder, Considered as One of the Fine Arts." He is considered the first to analyze murder aesthetically rather than ethically. In The Aesthetics of Murder (1991) Joel Black goes even further, stating that the murderer has to be called an artist if his performance evokes an aesthetic response in the spectator (39). Regarding our sympathy towards the killer, Murray Smith elaborates on the relations between the reader/viewer and the murderer arguing that the observer forms a partial or perverse allegiance with the murderer.

In spite of the fact that pain and torment are indispensable in murder literature and film, they are aestheticized in many ways, so that the reader/viewer craves them even more. Beautified depictions of violence often mask the horrific aspect of crime, 
encouraging people to enjoy the murder without being overwhelmed or repulsed. Not only does aestheticization of violence aim to present murder in a less appalling manner, but it also attempts to humanize the killer. Moreover, the technique allows the audience to "become" killers without the guilty conscience, by reminding them that the violence is not real, and therefore that it may be enjoyed without any moral or legal consequences.

\section{References}

Allue, Sonia B. 2002. "The Aesthetics of Serial Killing: Working against Ethics in the Silence of the Lambs (1988) and American Psycho (1991)." Atlantis. Journal of the Spanish Association for Anglo-American Studies 24 (2): 7-24.

Baldick, Chris. 2001. The Concise Oxford Dictionary of Literary Terms. $2^{\text {nd }}$ ed. New York: Oxford University Press.

Black, Joel. 1991. The Aesthetics of Murder: A Study in Romantic Literature and Contemporary Culture. Baltimore and London: The Johns Hopkins University Press.

Burke, Edmund. (1757) 1990. A Philosophical Enquiry into the Origin of our Ideas of the Sublime and Beautiful, ed. Adam Phillips. Reprint, New York: Oxford University Press.

De Quincey, Thomas. (1827) 2015. “On Murder, Considered as One of the Fine Arts.” In Murder Considered as One of the Fine Arts. Ebook. The University of Adelaide. www.ebooks. adelaide.edu.au

Donovan, Patricia. 2007. “America's Fascination with Murder.” Ebook. University at Buffalo. Accessed February 20, 2016. www.buffalo.edu

Gronstad, Asbjorn. 2008. Transfigurations: Violence, Death and Masculinity in American Culture. Amsterdam: Amsterdam University Press.

Halttunen, Karen. 2001. Murder Most Foul: The Killer and the American Gothic Imagination. Cambridge and London: Harvard University Press.

Knox, Sara L. 1998. Murder: A Tale of Modern American Life. Durham and London: Duke University Press.

Morrison, Robert. 2009. The English Opium-Eater: A Biography of Thomas De Quincey. Ebook. London: Weidenfeld \& Nicolson. www.amazon.com

Pinedo, Isabel C. 1997. Recreational Terror: Women and the Pleasures of Horror Film Viewing. New York: State University of New York Press.

Prince, Stephen. 2000. Screening Violence. New Brunswick, New Jersey: Rutgers University Press.

Rodbjerg, Morten J. 2015. Aesthetic Killers: Justification of Protagonist Violence in Modern American Cinema. Ebook. Amazon Digital Services LLC. www.amazon.com

Schneider, Steven J. 2001. "Murder as Art/The Art of Murder: Aestheticising Violence in Modern Cinematic Horror.” In Necronomicon: The Journal of Horror and Erotic Cinema, Book 4. ed. Andy Black. 65-85. London: Noir Press.

Seltzer, Mark. 1998. Serial Killers: Death and Life in America's Wound Culture. New York: Routledge. 
Pobrane z czasopisma New Horizons in English Studies http://newhorizons.umcs.pl Data: 26/04/2023 04:12:43

Smith, Murray. 1999. "Gangsters, Cannibals, Aesthetes, or Apparently Perverse Allegiances." In Passionate Views. Film, Cognition, and Emotion. eds. Carl Plantinga and Greg M. Smith. 217-238. Baltimore \& London: Johns Hopkins University Press.

Smith, Murray. 2011. "Just What Is It That Makes Tony Soprano Such an Appealing, Attractive Murderer?" In Ethics at the Cinema. eds. Ward E. Jones and'Samantha Vice. 66-90. New York: Oxford University Press.

Smith, Murray. 1995. Engaging Characters: Fiction, Emotion and the Cinema. Oxford: Clarendon Press. 